\title{
O [Não] Lugar Religioso dos Pentecostais no Campo Religioso Brasileiro
}

Fernanda Lemos ${ }^{1}$

\section{RESUMO}

A modernidade, bem como as novas formas de experienciar a religiosidade neste período, tem contribuído para que o sujeito religioso se organize de forma e em espaços diferentes do tradicional. No campo religioso brasileiro, esse fenômeno pode ser observado entre evangélicos que diariamente, a caminho do trabalho secular, realizam cultos pentecostais nos vagões de trem no Estado de São Paulo. Tal prática tem mostrado a organização de um grupo que expressa sua religiosidade em um 'não-lugar-religioso', independentemente da instituição religiosa da qual faz parte, porém reproduzindo a ética pentecostal neste espaço público. Neste sentido, esta comunicação tem como objetivo principal analisar a relação entre religião e modernidade através do encontro entre o tradicional (ética pentecostal) e o contemporâneo (culto religioso nos trens urbanos) e as novas reelaborações deste grupo específico (pentecostais) no campo religioso brasileiro.

\section{PALAVRAS CHAVE}

Identidade Pentecostal; Não Lugar Religioso; Modernidade.

\begin{abstract}
Modernity as well as new ways of experiencing religion in this period, has contributed to the religious subject is organized manner and

\footnotetext{
${ }^{1}$ Fernanda Lemos, mestre e doutora em Ciências da Religião pela Universidade Metodista de São Paulo, é professora Adjunto da Universidade Federal da Paraíba, onde coordena o Programa de Pós-Graduação em Ciências das Religiões.
} 
in different spaces of the traditional. In the Brazilian religious field, this phenomenon can be observed among evangelicals daily, the path of secular work, perform Pentecostal services in railway carriages in the State of São Paulo. This practice has shown the organization of a group expressing their religiosity on a 'no religious place', regardless of the religious institution to which it belongs, but reproducing ethics Pentecostal public space. In this regard, this communication aims at analyzing the relationship between religion and modernity through the encounter between traditional (Pentecostal ethics) and contemporary (religious worship in urban trains) and the new reworkings of this specific group (Pentecostal) in the Brazilian religious field.

\section{KEYWORDS}

Identity Pentecostal, No religious Place; Modernity.

\section{O lugar do sagrado na modernidade}

A religião faz parte da cultura, tanto quanto a arte, a política e a educação. E como um recurso cultural (Geertz, 1989) ela é historicizada e passível de todas as transformações decorrentes da sociedade. O ser humano, um ser cultural e histórico, tem a capacidade de se adequar à sua religião, ao seu tempo e a sua necessidade. Por mais que o campo religioso tente se estabilizar enquanto imutável e absoluto, com suas tradições cristalizadas, 'suas verdades' têm se adequado aos processos sociais da modernidade.

E neste contexto observamos um fenômeno com características peculiares no período contemporâneo, cuja dinâmica e história tornaram-se nosso objeto de pesquisa, um movimento religioso denominado 'Cruzada Evangelística Interdenominacional nos Trens das Boas Novas' - $\mathrm{CEI}^{2}$.

\footnotetext{
${ }^{2} \mathrm{O}$ culto religioso realizado pela CEI é um desses fenômenos de característica moderna. Tem como fundamento principal a prática cotidiana de cultos evangélicos nos vagões de trem e, para isso, conta com a associação de homens e mulheres que utilizam esse meio de transporte para o trabalho secular. Nesse trajeto assumem o compromisso de realizar esse trabalho religioso. Os arranjos sociais que estes indi-
} 
É um grupo com característica pentecostal que atua desde 1980 realizando cultos diários no $4^{\circ}$ vagão dos trens da 'Companhia Paulista de Trens Metropolitanos do Estado de São Paulo'. Esse culto tem a participação de homens e mulheres que, a caminho do trabalho secular, durante o período de viagem, realizam o trabalho religioso.

Apesar dos sujeitos atuarem cotidianamente no trabalho religioso da CEI, eles pertencem a instituições religiosas tradicionais. $\mathrm{O}$ trabalho religioso na igreja da qual se declaram membros se dá concomitantemente ao realizado nos trens, o que nos faz caracterizá-los no movimento enquanto associados e/ou integrantes. A fixidade do lugar de culto nos trens, a reunião diária com os mesmos integrantes, a característica pentecostal, dentre outros, demonstram características de institucionalização do movimento, que atua nos trens há 30 anos e não se deixou cooptar por nenhuma instituição religiosa tradicional, apesar da considerável presença de associados membros das Assembleias de Deus.

Em sociedades pré-tradicionais e até tradicionais a relação lugar e sagrado podia ser antropologicamente observável. Para isso podemos citar dois exemplos. O primeiro deles nos remete à sociedade de Israel (600 a.C.), onde o local é determinante no relacionamento com o sagrado. Deus, diferentemente da sociedade contemporânea em que 'o sagrado está em tudo e em todos', era revelado especificamente na cidade de Jerusalém. O segundo exemplo, mais atual, refere-se à religiosidade de Juazeiro do Norte, na Bahia, onde toda a formação de seu catolicismo popular se dá por meio de um milagre. O lugar, que até então era árido e pouco habitado, por causa da religião se torna um grande centro de peregrinação do nordeste brasileiro. A partir do milagre a cidade se constitui num símbolo sagrado, daí se desenvolve sua arquitetura, economia e política (SOUZA, 2009). No que se refere ao espaço, ambos os exemplos revelam a importância da relação entre religião e urbanização, "se considerarmos a imbricação entre espaço

\footnotetext{
víduos fazem são característicos da religiosidade contemporânea, ao mesmo tempo em que atuam nesse trabalho, enquanto associados da CEI, também possuem filiação religiosa institucional (geralmente pentecostal) e, ao mesmo tempo, visitam inúmeras outras instituições religiosas.
} 
urbano e organizações religiosas e a produção de sentido, veremos que a religião é um elemento eficaz nos processos de identificação e contestação da paisagem urbana" (THEIJE, 2006, p. 80).

Para outros analistas da vida urbana ressurgem com mais força, após os anos de 1970, os antigos Deuses, novos movimentos religiosos ou reaparecem projetos e esperanças messiânicomilenaristas. Com eles, a religiosidade volta a fazer parte da paisagem urbana e do convívio dos cidadãos, tornando-se a cidade, novamente, um local em que ganham força sistemas simbólicos até então tidos como definitivamente eliminados da vida urbana... Por outro lado, é possível que esse renascimento do misticismo ou da religião na cidade esteja ligado também à globalização ou à mundialização... Como resultado desse processo, novas configurações religiosas tomam conta do contexto urbano (CAMPOS, 2006, p. 163).

A religião no espaço urbano parece atender ao caos que se tornou a vida na cidade. Se outrora ela - a religião - havia sido confinada no espaço rural, de pequenos grupos, na modernidade ela reassume seu espaço em meio à massa populacional. Estando presente nos 'não-lugares' - onde há grande circulação de pessoas - como forma de atender às demandas individuais,

Não devemos, no entanto, nos esquecer que nesse contexto duas forças chocam-se: a dessacralização e a ressacralização. De um lado, estão as tradicionais instituições religiosas que perdem a força, fazendo surgir no lugar delas empreendimentos bem adequados à pós-modernidade. Essas forças derrubam fronteiras e identidades tradicionais... Nesse contexto, há um intenso processo de secularização ou de revanche do sagrado, que, segundo alguns estudiosos, tomam conta do meio urbano em escala crescente (CAMPOS, 2006, pp. 163-164).

Apesar da aparente força secularizante que a paisagem urbana moderna apresenta, a religião tem se tornado cada vez mais um objeto presente neste contexto. Ela parece atender a demanda instável e caótica deste 'não-lugar'. Por mais que os sujeitos sociais se sintam parte deste 
contexto urbano - em que aparentemente estão inseridos e parecem fazer parte orgânica dele (um coletivo individualizado) - as demandas sociais e pessoais formam um vácuo que se não pode ser resolvido com o consumo desenfreado (que gera um sentimento de pertença e conforto individual), pode ser preenchido pelos símbolos religiosos. Apesar do sentimento de pertença causado pelas grande circulação nos espaços urbanos, os conflitos sociais são tão intensos quanto nas sociedades tradicionais.

A modernidade pode ser explicada pelo deslocamento do espaço e pela individualização dos sujeitos (HERVIEU-LÉGER, 2008; AUGÉ, 2003). As mudanças de religião intrafamiliar parecem não mais causar grandes conflitos entre os sujeitos desse núcleo, uma vez que o fiel se tornou consumidor do capital simbólico proveniente desta circulação. Tanto fieis quanto igrejas mudam rapidamente, devido às rápidas transformações sociais, que fazem parte da própria sobrevivência dos sujeitos e das instituições. A mudança de religião não significa propriamente ruptura, mas, pode representar a combinação de elementos novos com os da religião de origem, que pode ter avanços e retrocessos (PRANDI, 1996 \& 1999).

Essa relativa independência contemporânea aliada ainda a elementos tradicionais da religião só é possível por causa do processo de secularização ${ }^{3}$, que imprimiu nos sujeitos a independência da instituição religiosa. Isto não significa que ela (religião) não exista mais enquanto realidade, mas que perdeu sua plausibilidade, seu poder legitimante totalitário. O sujeito religioso moderno é "movido" por suas necessidades, sem que isto lhe impute dano ou temor (SOUZA, 2001 \& 2004 \& 2006; PRANDI, 1999; AMARAL, 2003).

Segundo Sandra Duarte de Souza (2001), essa relativa autonomia dos sujeitos gerou um fenômeno peculiar na modernidade, o trânsito religioso, um forte indicador da recomposição entre religião e modernidade. Isso demonstra que o campo religioso brasileiro tem se adaptado

\footnotetext{
${ }^{3}$ Nossa compreensão sobre a secularização está baseada na teoria de Berger (1985, p. 119) ao compreender o termo como "o processo pelo qual setores da sociedade e da cultura são subtraídos à dominação das instituições e símbolos religiosos”. Isso pode ser observado na perda de plausibilidade da religião na sociedade (BERGER, 1985, p. 139).
} 
às demandas modernas dos sujeitos na sociedade secularizada. Dessa forma, podemos considerar que os sujeitos estão em constante processo de mudança, assim como os campos sociais e as instituições religiosas, para adaptarem-se às novas realidades sociais e culturais desse período "pós-tradicional".

Ao contrário de outros períodos históricos, a religião não é mais o centro exclusivo de regulação da estrutura social. Mas afinal, qual é o seu lugar na sociedade contemporânea? Segundo Hervieu-Léger (2008, p. 99), a prática peregrina - expressão da religiosidade móvel - "remete a uma outra forma de espacialização ${ }^{4}$ do religioso, que é a do percurso que ela traça, dos itinerários que ela baliza e sobre os quais os indivíduos se movimentam". Isso significa que o sagrado não depende mais exclusivamente do espaço ritual tradicional para ser expresso, como recurso individual ele acompanha o sujeito 'portador' da religiosidade.

Marc Augé (2003), em sua obra 'Não-Lugares', traz uma discussão fundamental para quem se aventura na discussão sobre a religiosidade moderna. E por mais que sua obra não se destine à compreensão do campo religioso, sua teoria é perfeitamente aplicável neste âmbito do conhecimento. Vivemos numa situação de "supermodernidade" em que a aceleração da história é um fato, e "os acontecimentos na maioria das vezes não [são] previstos pelos economistas, historiadores e sociólogos" (AUGÉ, 2003, p. 31). O atual período em que vivemos foi responsável por um deslocamento até mesmo do campo onde se realizava tradicionalmente a observação antropológica, que metodologicamente precisou ser revisitado.

Segundo ele, as interferências da supermodernidade na cultura e na sociedade resultam em reordenações significativas para compreensão antropológica,

Ela resulta, concretamente, em consideráveis modificações físicas: concentrações urbanas, transferências de população e multiplicação daquilo a que chamaremos "não-lugares", por opo-

\footnotetext{
${ }^{4}$ Grifo nosso.
} 
sição à noção sociológica de lugar, associada por Mauss e por toda uma tradição etnológica àquela de cultura localizada no tempo e no espaço. Os não-lugares são tanto as instalações necessárias à circulação acelerada das pessoas e bens (vias expressas, trevos rodoviários, aeroportos) quanto os próprios meios de transporte ou os grandes centros comerciais, ou ainda os campos de trânsito prolongado onde são estacionados os refugiados do planeta (AUGÉ, 2003, p. 36).

Na modernidade o que pode separar um "passageiro religioso" de um membro de igreja está marcado pelo espaço de circulação dos corpos e não pela diferença orgânica dos discursos e práticas sociais e religiosas. Por isso "não há mais análise social que possa fazer economia dos indivíduos, nem análise dos indivíduos que possa ignorar os espaços por onde eles transitam" (AUGÉ, 2003, p. 10).

Estamos diante de um fenômeno religioso moderno, em que o acesso à oferta simbólica está mediado não pela contribuição mensal, mas pela compra do bilhete de "passageiro", que pode dar acesso às mesmas ofertas, sem que seja necessária a identificação e filiação dos sujeitos. Não estamos falando em uma nova religião, mas de um movimento religioso que se adaptou ao tempo para sobreviver e continuar fornecendo símbolos a sujeitos secularizados, que sobrevivem em meio a uma cultura da mudança. "A paisagem religiosa da modernidade é caracterizada por um movimento irreversível de individualização e de subjetivação das crenças e das práticas... [o que permite] descrever a cena religiosa contemporânea como uma cena em movimento" (HERVIEU-LÉGER, 2008, p. 139).

O próprio lugar onde acontece o fenômeno religioso moderno é diferente dos lugares tradicionais, o que caracteriza estes espaços antropológicos como um não-lugar. Como é o caso dos 'Pregadores da Sé', homens que diariamente estão no ponto da cidade de São Paulo - aproveitando o grande número diário de circulação de pessoas - para pregarem a palavra de Deus, cantarem hinos evangélicos com violão e caixa de som, darem testemunhos de conversão pessoal e lerem a bíblia. Neste caso, a hipótese defendida por Augé para compreensão do não-lugar é de que, 
A supermodernidade é produtora de não-lugares, isto é, de espaços que não são em si lugares antropológicos e que, contrariamente à modernidade baudelairiana, não integram os lugares antigos: estes, repertoriados, classificados e promovidos a "lugares de memória", ocupam aí um lugar circunscrito e específico... onde se desenvolve uma rede cerrada de meios de transporte que são também espaços habitados (AUGÉ, 2003, p. 73).

São espaços de circulação de um grande número de pessoas, que em sua maioria não compartilha da mesma experiência religiosa do grupo. Entretanto, este não-lugar tradicional se tornou um lugar, visto que "o lugar e o não- lugar são, antes, polaridades fugidas: o primeiro nunca é completamente apagado e o segundo nunca se realiza totalmente palimpsestos em que se reinscreve, sem cessar, o jogo embaralhado da identidade e da relação" (AUGÉ, 2003, p. 74).

Augé demonstra que a modernidade não exclui os lugares, mas é produtora de outras possibilidades espaciais, há outras e necessárias concepções nessa nova antropologia supermoderna. Na verdade há uma animação do lugar, o lugar não existe porque quando o sujeito chegou neste lugar ele já estava ali; pelo contrário, na supermodernidade o lugar tem especificações simbólicas, tanto que ele só existe porque foi idealizado e construído pelos sujeitos (AUGÉ, 2003, p. 76).

Segundo Augé (1997, pp. 168-169), a compreensão antropológica dos mundos contemporâneos se dá a partir da compreensão espacial dos binômios do lugar e não-lugar. O lugar, segundo ele, tem características identitárias, relacionais e históricas. Ou seja, a constituição da identidade do indivíduo se dá na relação com os outros sujeitos e é marcada por alguma forma de símbolo que identifica historicamente este evento. Caso isso não ocorra, torna-se visível o não-lugar, contudo, o que é um não-lugar para determinado sujeito pode não ser para outro. Uma coisa é certa, "a multiplicação dos não-lugares, no sentido empírico, é, contudo, característica do mundo contemporâneo". Os não-lugares podem se tornar em lugares pela força da imposição simbólica que os sujeitos depositam nos espaços urbanos.

$\mathrm{O}$ que pode ser observado nos cultos do trem realizados pela CEI, o trabalho religioso desenvolvido pelo grupo está inserido e adaptado 
ao espaço urbano, às condições disponíveis para representação de sua crença. Apesar do aparente caos que configura o ambiente em movimento e da grande circulação de pessoas, na verdade, torna-se uma vantagem para propagação e emancipação do movimento. Nesse sentido, pessoas que afirmam 'não dispor de tempo para ir a uma igreja', encontram no culto do trem a possibilidade de presenciar e ouvir palavras e cânticos sagrados.

\section{O [não] lugar sagrado e sua caracterização como um lugar}

O local onde acontecem as manifestações religiosas da CEI tem suas peculiaridades. Para um culto religioso, o vagão de trem não seria o local mais apropriado para expressar a fé. Além de não se caracterizar como um espaço sagrado, as condições precárias e subumanas de transporte público, num primeiro momento, parecem limitar essa atividade cúltica. Entretanto homens e mulheres, além de suportarem uma rotina diária de aproximadamente onze horas (período de trabalho mais o período de viagem) de trabalho, geralmente braçal, ainda encontram motivação para participar diariamente das atividades desenvolvidas pela CEI.

A forma como manifestam suas religiosidades transforma aquele "não-lugar-sagrado" em um espaço cúltico, com orações, testemunhos, pregações, intercessão, apelo a novas conversões e muito louvor. O fenômeno religioso observado nos vagões de trem traz consigo características contemporâneas como "não-lugares" que se tornam lugares sagrados, liberdade religiosa no âmbito secular, além da tentativa, por um lado, de destradicionalizar-se religiosamente, mas por outro, a necessidade de racionalizar-se para sobreviver em meio à competitividade na diversidade religiosa.

O local onde acontece a manifestação dessa ação coletiva de característica religiosa é irreal em termos tradicionais, na verdade ele não existe, o que existe é a mobilidade dos sujeitos para tornar o trem num lugar sagrado, pelo menos naquelas horas de viagem. "Em condi- 
ções de modernidade, o lugar se torna cada vez mais fantasmagórico" (GIDDENS, 1991, p. 27).

Podemos perceber que o espaço do culto é um cenário que os atores utilizam por mais de uma hora e, quando terminado o espetáculo, as luzes se apagam e a platéia (tanto ouvintes quanto os membros da CEI) vai/volta para seus destinos. O espaço do vagão de trem só tem sentido quando os sujeitos estão reunidos em torno do mesmo objetivo. O que não é de se estranhar no contexto de modernidade, quando o "'lugar' é melhor conceitualizado por meio da ideia de localidade, que se refere ao cenário físico da atividade social como situado geograficamente" (GIDDENS, 1991, pp. 26-27).

Em grande parte das religiões pré-modernas os símbolos estão condicionados aos lugares sagrados. O lugar determina o sagrado, porque muitas vezes o sagrado determinou para aquela cultura o lugar. No caso do Judaismo primitivo, Jerusalém se torna o lugar específico para expressão genuína com o sagrado, é lá que Deus se revela para o seu povo. No caso do Islamismo, Meca é o lugar sagrado da revelação e necessário para contato com seu Deus e, quando da impossibilidade de estar neste lugar para adorar Deus, direcionar-se para lá ao menos é fundamental para orações diárias, pois o lugar é determinante nesta religiosidade. Nestes casos, especificamente, o lugar é determinado pela tradição, porém,

Os modos de vida produzidos pela modernidade nos desvencilharam de todos os tipos tradicionais de ordem social, de uma maneira que não têm precedentes. Tanto em sua extensionalidade quanto em sua intencionalidade, as transformações envolvidas na modernidade são mais profundas que a maioria dos tipos de mudança característicos dos períodos precedentes (GIDDENS, 1991, p. 14).

Giddens nos chama atenção para a mudança drástica que existe entre modos de vida pré-modernos e atuais, não há comparação, exceto pela distinção entre ambos. Dessa forma, seria impossível comparar as formas religiosas de "hoje" com as religiões de "ontem". Até mesmo dizer que a religião ' $x$ ' ou a religião ' $y$ ' é caracterizada por ' $n$ ' situações 
é um risco, pois, na contemporaneidade, não há mais uma religião determinante no comportamento individual. $\mathrm{O}$ coletivo ainda existe, entretanto é permeado pelas individualidades, o que não exclui o poder religioso, ele está mais difuso e descentralizado.

Voltemos ao lugar religioso na modernidade, ele existe e é importante na expressão religiosa, entretanto, não pode ser comparado a períodos pré-modernos. O lugar na modernidade é um "não-lugar"?

O não-lugar é diametralmente oposto ao lar, à residência, ao espaço personalizado. É representado pelos espaços públicos de rápida circulação, como aeroportos, rodoviárias, estações de metrô, e pelos meios de transporte - mas também pelas grandes cadeias de hotéis e supermercados. Só, mas junto com outros, o habitante do não-lugar mantém com este uma relação contratual representada por símbolos da supermodernidade, seja um bilhete de metrô ou avião, cartões de crédito ou o cartão telefônico, além de documentos - passaporte, carteira de motorista ou qualquer outro -, símbolos que, enfim, permitem o acesso, comprovam a identidade, autorizam deslocamentos impessoais (AUGÉ, 2003, [s.p.])5.

Ao que tudo indica o lugar de manifestação religiosa da CEI é um "não-lugar". Se assumirmos a posição teórica de Augé sobre a ideia de local na modernidade, os indicativos são de que nosso objeto de pesquisa é diferente de qualquer expressão religiosa pré-moderna. Segundo os critérios estabelecidos pelo autor para definir um "não-lugar" observamos que a CEI não possui um lugar personalizado, é um lugar público de rápida circulação, acontece num meio de transporte e o acesso ao espaço é mediado pela compra do bilhete para embarque. Os indivíduos “estão juntos, porém sós", são estabelecidas relações impessoais - pela compra do bilhete de embarque - apesar de diariamente se encontrarem nos mesmos horários.

$\mathrm{Na}$ antropologia tradicional os lugares observáveis eram fixos, no caso de nosso objeto tudo está em circulação, desde as pessoas até o próprio lugar onde é realizado o culto religioso. O lugar - aparente-

\footnotetext{
${ }^{5}$ Esta citação foi extraída da contracapa do livro de Augé 'Não-Lugares' (2003).
} 
mente impessoal - confere identidade aos sujeitos, a religiosidade dá coesão a motivação social de cultuar nos trens. O espaço do trem é fundamental para a existência deste movimento. $\mathrm{O}$ "não-lugar" em que a CEI realiza seus cultos se tornou um LUGAR,

O lugar e o não-lugar são, antes, polaridades fugidias: o primeiro nunca é completamente apagado e o segundo nunca se realiza totalmente - palimpsestos em que se reinscreve, sem cessar, o jogo embaralhado da identidade e da relação. Os nãolugares, contudo, são a medida da época: medida quantificável e que se poderia tomar somando, mediante algumas conversões entre superfície, volume e distância, as vias aéreas, ferroviárias e os domicílios móveis considerados "meio de transporte" (aviões, trens, ônibus)... (AUGÉ, 2003, pp. 74-75).

Quando Augé caracteriza os lugares e os não-lugares como polares, ele demonstra a dificuldade em compreender os lugares na modernidade. A distinção esbarra na dificuldade da realização do fenômeno. Um culto diário, com horário fixo, num vagão determinado, com pessoas fixas indica que apesar de os lugares da modernidade serem "fantasmagóricos", ou seja, lugares diferentes e assustadores para uma manifestação religiosa, o hábito fez desse espaço cúltico um lugar sagrado, pelo menos nos dias e horários especificados pelo movimento para o culto. O que torna o lugar sagrado não é a exclusividade destinada ao espaço físico para a realização das atividades religiosas, mas a ritualidade imposta sobre ele pelos seus atores, mesmo que seja provisório.

Em termos tradicionais, quando pensamos em um culto, imaginamos a reunião de pessoas em uma igreja, num determinado bairro e cidade, que quase diariamente se juntam num templo ornamentado pelos símbolos religiosos para expressão de suas religiosidades. Geralmente o templo tem dias e horários fixos para a abertura e sempre estará no mesmo lugar esperando pelos sujeitos religiosos, que vão em busca das mais variadas necessidades. Não é raro também, principalmente em igrejas protestantes tradicionais, que os membros tenham até mesmo lugares fixos para sentar, onde ninguém se atreve a se aproximar, em respeito aos membros mais antigos. $\mathrm{O}$ fato é que a ideia de um lugar 
'não fixo', como é o caso do culto do trem e oposto ao exemplo que acabamos de mencionar, causa estranheza por ser considerado expressão do sagrado, porque mesmo no contexto de modernidade, ainda temos a ideia de que o sagrado não muda nunca, bem como suas formas expressivas. Tanto muda que a forma de expressá-lo e o seu lugar tem se adaptado às necessidades dos sujeitos, que passam em média 12 horas diárias no trabalho secular e a caminho dele. A religião vem se adaptando as novas composições sociais. A criatividade dos sujeitos em adaptar a realidade caótica e subumana dos trens em um culto cheio de beleza, cântico e orações é um desafio estético.

A religiosidade expressa no trem percorre quilômetros e não é fixada por uma cidade ou bairro, ela vai passando pelos bairros de São Paulo e acontecendo. Além do lugar do culto ser um não-lugar, ao exemplo de Augé (2003), está o tempo todo em movimento. O que os evangélicos contemplam no momento do culto é a paisagem periférica que perpassa pela janela do trem. A linha em que a CEI atua é a que percorre a zona leste do estado de São Paulo, da estação Brás até Calmon Viana, totalizando 13 diferentes estações, em treze diferentes lugares.

Dessas treze estações, 4 pertencem a cidades da grande São Paulo. A viagem dura aproximadamente uma hora e trinta minutos, se considerarmos usuários que viajam de um extremo a outro (Brás - Calmon Viana). O culto começa, geralmente, em Itaquaquecetuba, local onde a maioria dos membros da CEI começam a embarcar e termina na estação do Brás, ponto final da linha leste, mas com acesso ao metrô e outras áreas de São Paulo.

Enquanto 13 estações são percorridas com o trem em alta velocidade, os evangélicos da CEI transformam um ambiente sofrível e quase que insuportável num lugar de manifestação religiosa. $\mathrm{O}$ fato de o $4^{\circ}$ vagão ser o "vagão dos crentes" só o é pelo fato dos atores sociais, neste caso religiosos, representarem seus papéis diariamente, por isso, o que para Augé (2003) é característico da supermodernidade - o não-lugar exercido pelos passageiros do trem - não é aplicado de forma definitiva e fechada para o fenômeno observado. No caso dos sujeitos da CEI há o pagamento do bilhete de passagem para o direito de utilização do meio de transporte, mas há também o encontro pré-fixado com o coletivo, 
com os membros do movimento. Não são apenas ações individualizadas, o encontro no $4^{\circ}$ vagão com os demais membros do grupo os torna mais que trabalhadores, confere-lhes identidade religiosa. A experiência solitária do não-lugar cede espaço à convivência coletiva do lugar, em um espaço considerado "não-lugar".

Abaixo observamos uma cena rara nos dias de semana, o espaço do vagão do trem vazio. Não é possível notar nenhuma forma de símbolo religioso neste lugar, mesmo porque o fim a que se destina este vagão é o transporte público da população de baixa renda residente na zona leste de São Paulo. Nota-se que os assentos são mínimos, a grande maioria dos trabalhadores viaja em pé. São apenas quatro portas de cada lado para descer e subir muitas pessoas ao mesmo tempo, o que dificulta a entrada e a saída nos vagões, além do mais, em dias quentes o calor é insuportável. Homens e mulheres se aglomeram por mais de uma hora e meia, praticamente uma justaposição humana, não há necessidade de apoiar as mãos sobre as barras de ferro, é impossível cair, visto que nem ao menos dá para se mexer.

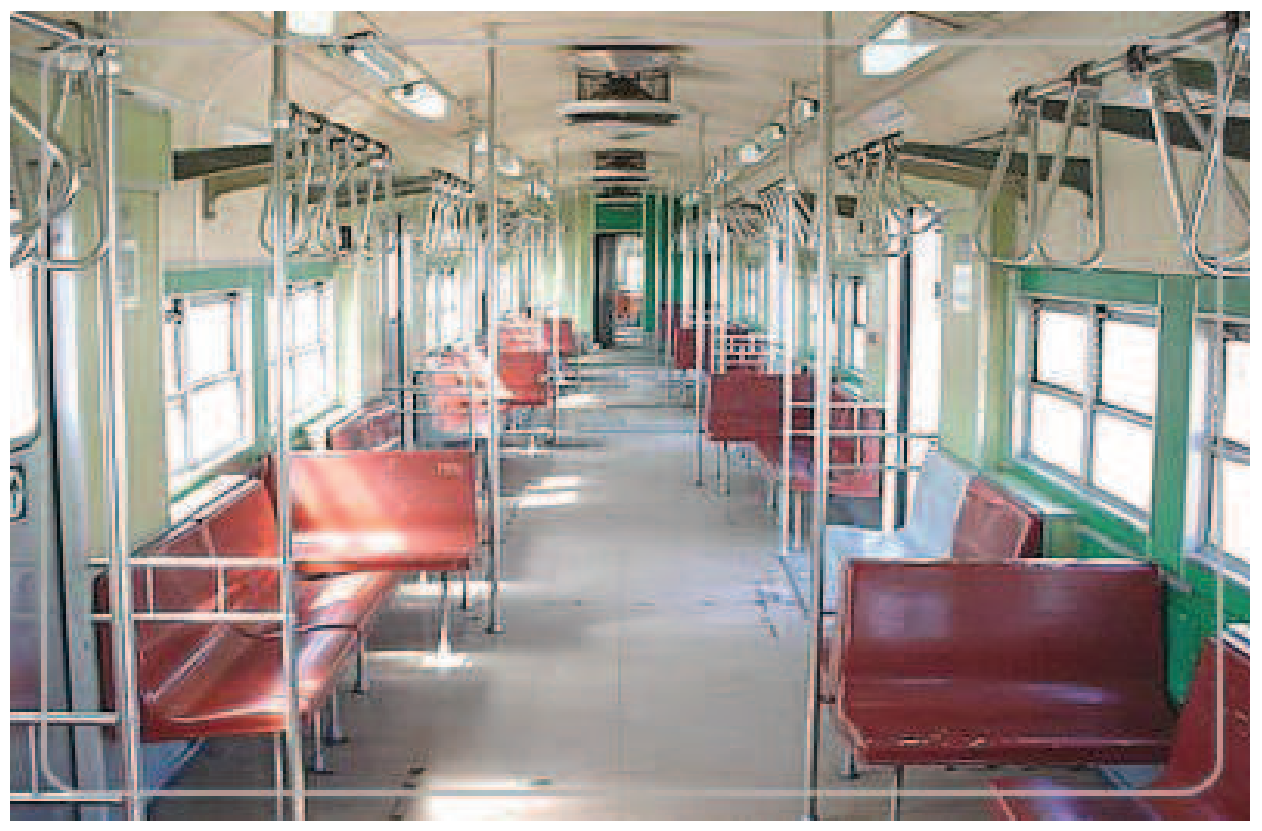

Vagão de trem vazio ${ }^{6}$

\footnotetext{
${ }^{6}$ Imagem extraída do site oficial da CPTM, fonte: http://www.cptm.sp.gov.br/e_frota/ frota/default.asp., em 06/02/2009.
} 
Já na imagem abaixo observamos a ação dos sujeitos religiosos no $4^{\circ}$ vagão:

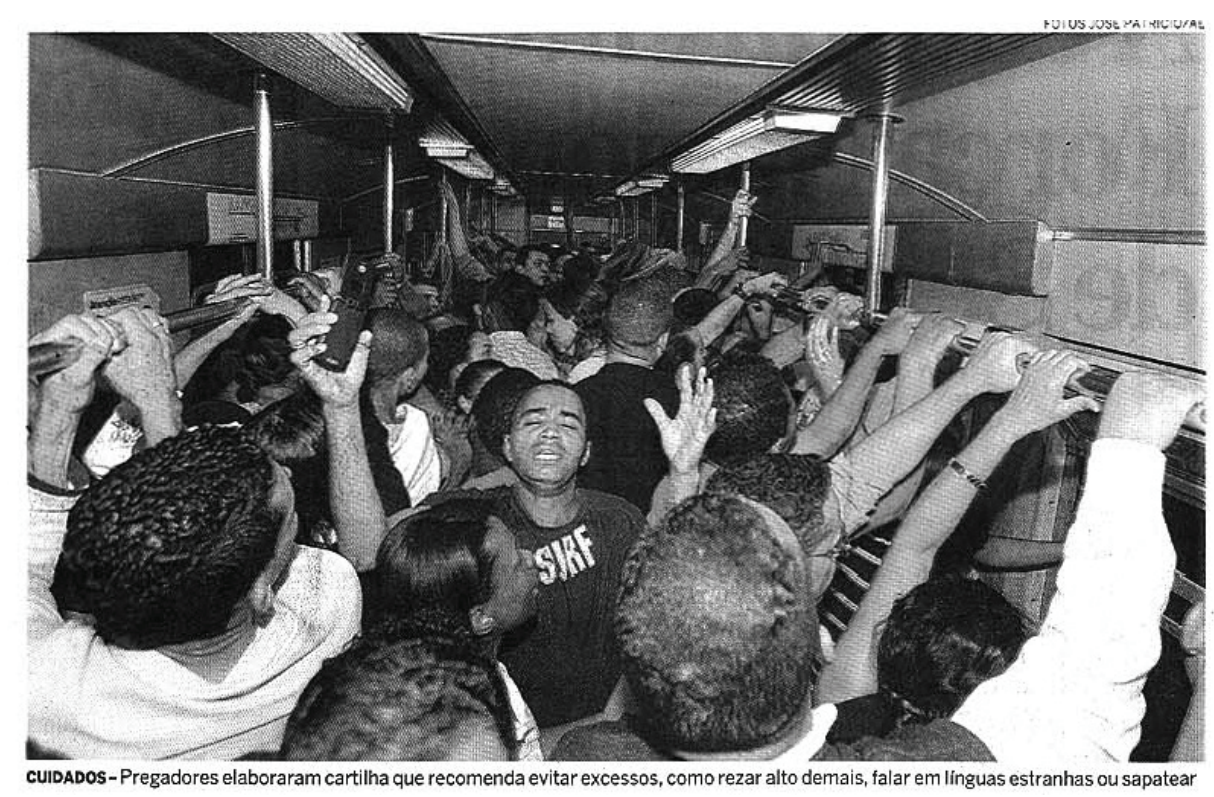

Vagão de trem lotado no momento do culto ${ }^{7}$

Contrapondo as imagens visualizadas do vagão vazio, observamos aquilo que já temos analisado desde o início de nossa discussão sobre o lugar antropológico. O trem não é um espaço religioso, entretanto, a ação coletiva dos sujeitos confere a um não-lugar seu status de 'lugar sagrado', não pelo espaço em si, mas pela motivação coletiva dos indivíduos. O vínculo contínuo de trabalhadores que cultuam há mais de 28 anos nos trens lhes confere identidade religiosa neste espaço secular.

Se pensarmos os indivíduos, que utilizam o trem como meio de transporte para locomoção ao trabalho secular, sim, esses são passageiros do não-lugar. Mas os membros da CEI não são meramente passageiros. A organização do trabalho religioso nos trens tornou-os sujeitos religiosos de um lugar específico, que pode não ser convencional e nem tradicional, mas já é identificado como o "vagão dos crentes". O próprio Augé reconhece que lugares e não-lugares se opõem, não há possibilidades de se estabelecer fronteiras fixas de onde começa um e

\footnotetext{
${ }^{7}$ Imagem fonte: "O Estado de S. Paulo", de 06 de julho de 2008, por José Patrício.
} 
quando termina o outro, afinal estamos num contexto de modernidade, "nos não-lugares da supermodernidade, sempre há um lugar específico" (AUGÉ, 2003, p. 101).

$\mathrm{Na}$ realidade concreta do mundo de hoje, os lugares e os espaços os lugares e os não-lugares misturam-se, interpenetram-se. A possibilidade do não-lugar nunca está ausente de qualquer lugar que seja. A volta ao lugar é o recurso de quem frequenta os nãolugares... (AUGÉ, 2003, 98).

O sujeito religioso que participa dos cultos da CEI há muito deixou de ser meramente um passageiro. Atualmente, os evangélicos que compõem esse movimento são reconhecidos como integrantes de uma expressão religiosa. Dentre os motivos para o reconhecimento estão: a vestimenta, o comportamento e, principalmente, o agrupamento no $4^{\circ}$ vagão, lugar que se tornou sagrado pela motivação coletiva dos trabalhadores e trabalhadoras.

Apesar de seus associados considerarem a CEI uma igreja, pelo fato da igreja referida por eles ser um agrupamento de crentes, ela não o é, pelo menos não no sentido estrutural do termo. A CEI é um movimento religioso de característica pentecostal, que, desde o início, apresenta indícios de institucionalização, que vem se confirmando, ultimamente, na luta pela fixidade do lugar sagrado no $4^{\circ}$ vagão dos trens da CPTM.

\section{Referências}

AMARAL, Leila. Deus é pop: sobre a radicalidade do trânsito religioso na cultura popular de consumo. SIEPIERSKI, Paulo D. \& GIL, Benedito M. (Orgs.). Religiões no Brasil: enfoques, dinâmicas e abordagens. São Paulo: Paulinas. 2003, pp. 97-108. (Coleção estudos da ABNR)

AUGÉ, Marc. Não-Lugares: introdução a uma antropologia da supermodernidade. Trad. Maria Lúcia Pereira. $3^{\circ}$ edição. Campinas: Papirus, 2003. (Coleção Travessia do Século). 
AUGÉ, Marc. Por uma antropologia dos mundos contemporâneos. Trad. Clarisse Meireles \&Leneide Duarte. Rio de Janeiro: Bertrand Brasil, 1997.

BERGER, Peter L. O dossel sagrado: elementos para uma teoria sociológica da religião. Trad. José Carlos Barcellos. 3a ed. São Paulo: Paulus, 1985. (Col. Sociologia e Religião 2).

CAMPOS, Leonildo Silveira. Indicadores sociais e afiliação religiosa no "Grande ABC" Paulista. Estudos de Religião. Ano XX, n. 31. São Bernardo do Campo: Metodista, 2006, pp. 154-193.

GEERTZ, Clifford. A interpretação das Culturas. Rio de Janeiro: LTC Editora, 1989.

GIDDENS, Anthony. As conseqüências da modernidade. Trad. Raul Fiker. São Paulo: UNESP, 1991. (Biblioteca básica).

GIDDENS, Anthony. Modernidade e identidade. Trad. Plínio Dentzien. Rio de Janeiro: Jorge Zahar Editor, 2002.

HALL, Stuart. A identidade cultural na pós-modernidade. $9^{\circ}$ edição. Trad. Tomaz Tadeu da Silva \& Guacira Lopes Louro. Rio de Janeiro: DP\&A editora, 2004.

HERVIEU-LÉGER, Danièle. O peregrino e o convertido: a religião em movimento. Trad. João Batista Kreuch. Petrópolis: Vozes, 2008. PRANDI, Reginaldo. As religiões, a cidade e o mundo. A Realidade Social das Religiões no Brasil: religião sociedade e política. São Paulo: HUCITEC, 1996, pp. 23-34.

PRANDI, Reginaldo. Religião, biografia e conversão: escolhas religiosas e mudanças de religião. IX Jornada sobre Alternativas religiosas na América Latina. Mesa redonda "minorias religiosas em contexto: conversão e suas relações sociais e políticas". Rio de Janeiro: IFCS/UFRJ, 21-24 de setembro de 1999, pp. 1-15.

SOUZA, Sandra Duarte. "Gênero, religião e modernidade". Mandrágora, Ano IX, $n^{\circ} 10$, 2004. São Bernardo do Campo: UMESP/NETMAL, pp. 6-7.

SOUZA, Sandra Duarte. Trânsito religioso e construções simbólicas temporárias: uma bricolagem contínua. Revista Estudos de Religião, Ano XV, $n^{\circ}$ 20, São Bernardo do Campo/SP: UMESP, janeiro-junho/2001, pp. 157-167. 
SOUZA, Sandra Duarte. Violência de gênero e religião: alguns questionamentos que podem orientar a discussão sobre a elaboração de políticas públicas. Mandrágora: Gênero, Religião e Políticas Públicas. Ano 13, n. 13. São Bernardo do Campo: Metodista, 2007, pp. 15-21. TAVARES. Fátima Regina Gomes. A sociologia da religião na modernidade religiosa: notas sobre alguns dilemas atuais. Estudos de Religião. Ano XX, no 30. São Bernardo do Campo: Metodista, 2006, pp. 85-94.

THEIJE, Marjo de. Religião e transformações urbanas em Recife, Brasil. MARIANO, Ricardo (Org.). Ciencias Sociales y Religión, Año 8, $\mathrm{n}^{\mathrm{o}}$ 8. Porto Alegre: Asociación de Cientistas Sociales de La Religión Del Mercosur. Octubre de 2006, pp. 63-84.

WILLAIME, Jean-Paul \& HERVIEU-LÉGER, Danièle. Sociologia e religião, abordagens clássicas. Trad. Ivo Storniolo. Aparecida: Idéias\& Letras, 2009. (Coleção Sujeitos e Sociedades) 